\title{
A Free-Piston Stirling Engine/Linear Alternator Controls and Load Interaction Test Facility
}

Jeffery S. Rauch

Sverdrup Technology, Inc.

Lewis Research Center Group

Brook Park, Ohio

M. David Kankam and Walter Santiago

National Aeronautics and Space Administration

Lewis Research Center

Cleveland, Ohio

and

Frank J. Madi

Sverdrup Technology, Inc.

Lewis Research Center Group

Brook Park, Ohio

Prepared for the

27th Intersociety Energy Conversion Engineering Conference sponsored by the Society of Automotive Engineers

San Diego, California, August, 3-7, 1992 
$=-r$. 


\section{A Free-Piston Stirling Engine/Linear Alternator \\ Controls and Load Interaction \\ Test Facility}

by:

Jeffrey S. Rauch

M. David Kankam

Walter Santiago

Frank J. Madi
Sverdrup Technologies, Inc., Cleveland, Ohio

NASA Lewis Research Center, Cleveland, Ohio

NASA Lewis Research Center, Cleveland, Ohio

Sverdrup Technologies, Inc., Cleveland, Ohio

\section{ABSTRACT}

A test facility at NASA Lewis has been assembled for evaluating: free-piston Stirling engine/ linear alternator control options, and interaction with various electrical loads. This facility is based on a "SPIKE" engine/alternator. The paper describes the engine/ alternator, a multi-purpose load system, a digital computer based load and facility control, and a data acquisition system with both steady-periodic and transient capability.

Preliminary steady-periodic results are included for several operating modes of a digital AC parasitic load control. Preliminary results on the transient response to switching a resistive $\mathrm{AC}$ user load are discussed.

\section{INTRODUCTION}

NASA's Civil Space Technology Initiative, High Capacity Power Program [1] has the objective of providing significant improvements in the technology associated with space nuclear power. A key part of this program involves the development of the free-piston Stirling engine/linear alternator (FPSE/LA) as a viable high-efficiency thermal-toelectric power converter. Development of the Controls and Load Interaction Test Facility is an integral part of this overall effort. The objectives of this facility are to evaluate power conditioning and control needs of FPSE/LA based power systems. Initially a single engine system with various electrical loads is being tested to characterize the steady-state and transient characteristics of a typical FPSE/LA.

The FPSE dynamics literature reviewed in [2] has described these engines analytically. Though some [3] have compared calculated and experimental results, little experimental data has been published. The literature largely ignores the influence of the linear alternator and electrical load on the dynamics of FPSE systems. Even less experimental verification of transient analysis has been completed. The facility described herein is specifically designed to address these needs.

\section{TEST FACILITY HARDWARE}

ENGINE/ALTERNATOR - The FPSE/LA is the principle facility component, Fig 1 . Several "SPIKE"

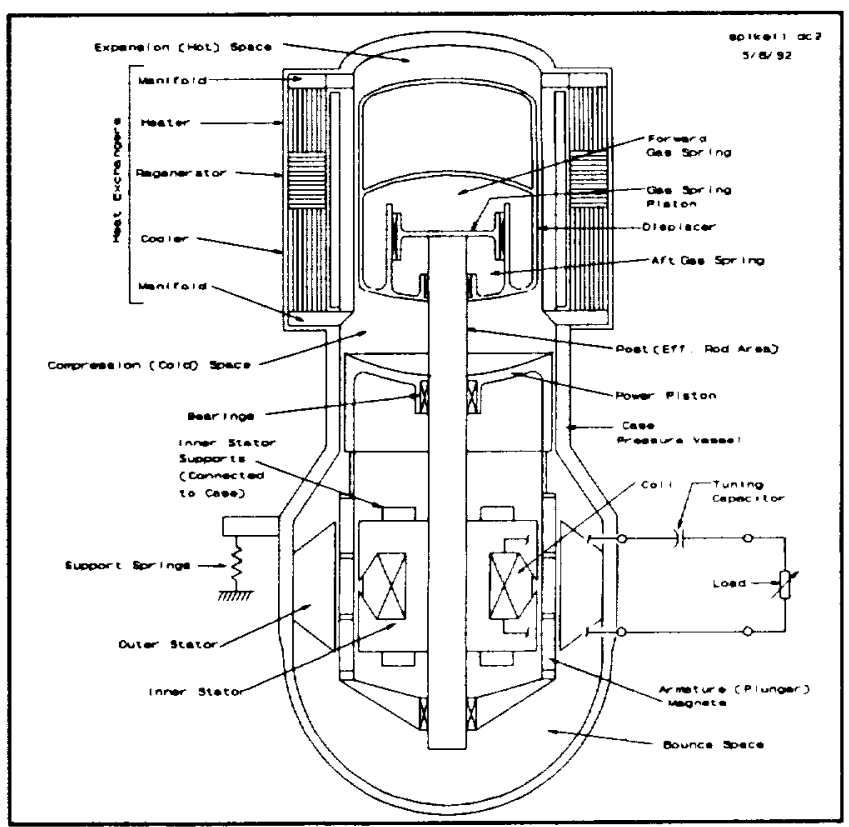

Figure 1 Schematic of SPIKE Engine.

FPSE/LAs were built by Sunpower Inc. in 1983-84 [4 \& 5]. The original engine was built for $\mathrm{Ft}$. Belvoir, other nearly identically engines were built for DOE and NASA.

Although the detailed geometry of SPIKE is different from other FPSE/LAs, its dynamic topology, Fig 2, is similar to several other engine/alternators of current interest to NASA, including: NASA's SPDE/SPRE $[6,7,8]$ and CTPC [9], (designed and fabricated by Mechanical Technology) and the ASCS engine [10] (designed by Cummins Power Generation). 


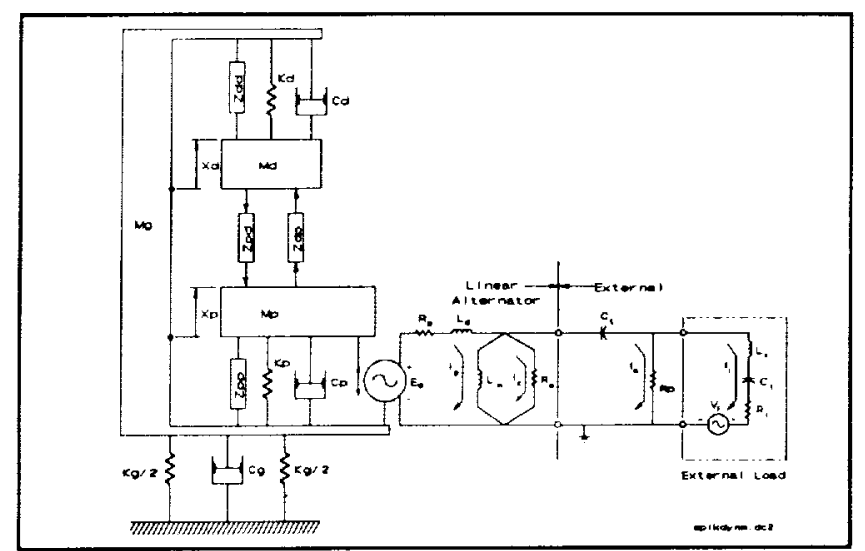

Figure 2 Dynamic Model.

For purposes of the controls and load interaction tests, the major parts of the FPSE/LA are the mechanical and electrical dynamic components, Fig $1 \& 2$. The three mechanical dynamic components are the displacer, piston and case. Both the displacer and piston are free to oscillate relative to the engine case or pressure vessel. They are radially supported by sliding bearings on a central post which is attached to the casing in the bounce space and runs through the piston and bottom of the displacer. These bearings influence the SPIKE engine dynamics by contributing Coulomb damping to the displacer to case $\left(c_{d}\right)$ and piston to case $\left(c_{p}\right)$ damping. In engines with gas bearings (e.g. SPRE \& CTPC) this damping is negligible.

A gas spring piston, Fig. 2, is attached to the forward end of the post and runs in a close fitting cylinder in the displacer. This forms an inside-out double-acting gas spring between the displacer and case, $\left(k_{d}\right)$ in Fig 2 . Gas spring thermal hysteresis and leakage losses also contribute to the displacer-to-case damping, $\left(c_{d}\right)$. The displacer's projected expansion space area is larger than that of the compression space by the post or rod area $\left(A_{t}\right)$. The thermodynamic cycle pressure acting on this area provides the power necessary to drive the displacer.

The power piston separates the thermodynamic working space, above the piston, from the "bounce" space, below the piston. The pressure developed by the thermodynamic cycle acting on the piston area $\left(A_{p}\right)$ drives the piston and alternator plunger. The "bounce" space is a weak, but measurable, gas spring between the piston and casing $\left(k_{p}\right)$. Gas spring thermal hysteresis and leakage losses in the bounce space also contribute to the piston-to-case damping, $\left(c_{p}\right)$. The major "spring" acting on the piston is the working space itself $\left(Z_{p p}\right)$.

There are no direct mechanical springs or dampers coupling the displacer and piston in the SPIKE. However, the thermodynamic cycle does pneumatically couple these components, $\left(Z_{p d}, Z_{d p}\right)$. This engine topology is sometimes referred to as an absolute displacer configuration, since the displacer is sprung to the case rather than the power piston.

The casing of the SPIKE engine is relatively light, though it is the most massive of the three dynamic components. The casing is isolated from the test stand by sev- eral mechanical springs. Due to its low mass and spring supports, the casing motion is significant.

The alternator is a "conventional" moving permanent magnet linear alternator. Two plunger (armature) segments are directly connected to the power piston. The plunger, containing radially polarized magnets, oscillates in an "air" gap between the inner and outer stators. The magnetic polarity reverses as the piston moves from one end of its stroke to the other. The inner and outer stators are laminated magnet steel providing a low reluctance flux path around the coil. The stators are mounted to the casing via a bridge structure that runs between the plunger segments. The coil, located in the inner stator, is connected to the external load circuit.

Annular heat exchangers, located around the displacer, connect the hot expansion space to the cold compression space. These constitute a major portion of the engines working space volume.

The heat source is an unrecouperated premixed natural gas combustor. Although lack of a recouperator substantially reduces system efficiency, this combustor has proven to be simple and reliable to operate. Low combustor efficiency does not affect the engine dynamics and therefore has no impact on the test objectives.

Heat is transferred from the combustor to the working fluid in the heater section through a cylindrical section of the monolithic heater head. The gas heat transfer is enhanced with axially oriented fins on both the external (combustor) side and internal (working fluid) side of the pressure wall in the heater section. An annular regenerator is located between the heater and cooler. The regenerator matrix is made of stainless steel woven rope (Metex). Heat is transferred from the thermodynamic cycle to the cooling water through a finned annular cooler. The working gas side of the cooler is axially finned while the coolant side is circumferentially finned.

The heat exchangers are essential to the operation of the free-piston Stirling engine. They impact the dynamics by maintaining the thermodynamic temperature ratio necessary for engine operation. Also, since they contribute to the thermodynamic volume, they have a first order effect on the pressure amplitude. This affects both the power and the "stiffness" of the thermodynamic cycle. Finally, the heat exchanger pressure drop acting on the displacer area $\left(A_{d}\right)$, less the rod area $\left(A_{\gamma}\right)$, results in a damping force on the displacer.

MULTI-PURPOSE LOAD - Figure 3 is a schematic of the general purpose load and control system developed for this facility. The alternator terminals ( $A$ and $G$ ) are connected to a series tuning capacitor (A-B), which balances the inductive reactance of the linear alternator. The tuning capacitance is adjustable from 49 to $139 \mu \mathrm{f}$, in steps of $6 \mu \mathrm{f}$, by switching capacitors $\mathrm{C} 2$ to $\mathrm{C} 5$. Several parallel loads can be connected to the AC output terminals (B-G) including: an AC digital control load, AC user load(s), a DC analog control load, a DC user load and an emergency load. The DC loads are connected to the AC terminals via an isolation transformer and full-wave rectifier. The DC bus 
can be either unfiltered or filtered by installing a jumper (J1) to a $11,600 \mu \mathrm{f}$ shunt capacitor $(\mathrm{Cl})$. The $\mathrm{AC}$ digital control load consists of 8 parallel coarse resistances $\left(R_{c}\right)$, each rated for $325 \mathrm{~W}$ at $115 \mathrm{~V}$, and 8 parallel fine resistances $\left(R_{f}\right)$ which have binarily increasing resistance. The total fine load is equivalent to 1 coarse load. The AC control load is capable of dissipating from $1 \mathrm{~W}$ to $2.9 \mathrm{~kW}$ (at $115 \mathrm{~V}$ ). These control resistors are connected to the $\mathrm{AC}$ power bus by zero-crossing type solid-state relays (S) which are controlled by the Digital Engine Control (DEC). The DEC determines the required control load, and directly controls the state of the coarse and fine load relays.

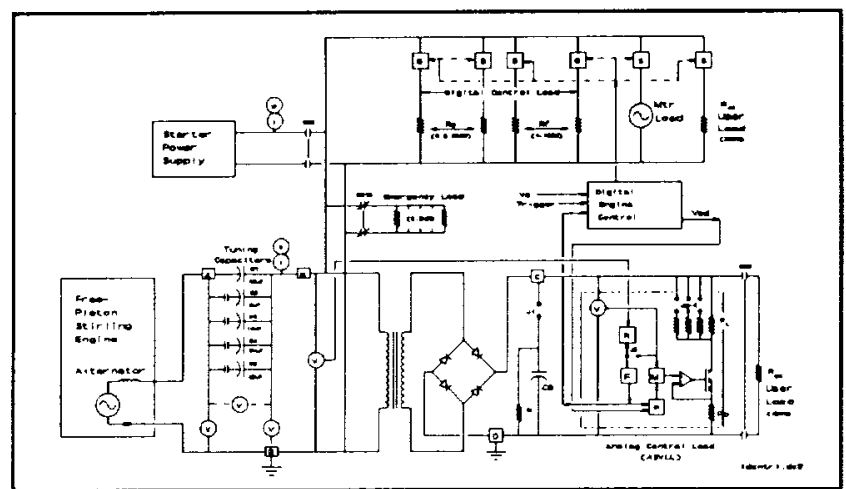

Figure 3Controls rig load schematic.

The shunt resistance for the DC analog control load is an "Analog Synthesized Variable Linear Load" (ASVLL) [11]. Power is dissipated in 1 to 4 parallel load resistances $\left(R_{\mathfrak{L}}\right)$ which are connected in series with 4 parallel connected power MOSFETs and a small current sense resistor $\left(R_{o}\right)$. The MOSFETs are operated in their active (non-saturated) region. A feed-back circuit, consisting of an analog multiplier (M) and operational amplifier, controls the conductance of the MOSFETs to enforce a linear relation between instantaneous voltage drop (across the MOSFETs) and current. The operational amplifier driving the MOSFET gates implements the following equality:

$$
\text { i } R_{\mathrm{o}}=\mathrm{V}_{\mathrm{B}} \mathrm{kv}
$$

where (i) is the instantaneous current, $\left(R_{\mathrm{o}}\right)$ is a small current sensing resistance, $\left(V_{B}\right)$ is the output of the voltage control and $(k)$ is the product of the multiplier gain constant and voltage divider factor which is applied to the instantaneous DC bus voltage ( $v)$. Thus the circuit appears as a resistance:

$$
\mathrm{R}=\mathrm{v} / \mathrm{i}=\mathrm{R}_{\mathrm{o}} /\left(\mathrm{k} \mathrm{V}_{\mathrm{B}}\right)
$$

connected to the DC bus.

The set point voltage $\left(\mathrm{V}_{\mathrm{sd}}\right)$ for the analog voltage control is determined by the DEC. The DEC acts as a master voltage controller when the DC control load is used. Either the AC (rms) or the DC bus voltage can be controlled (depending on a jumper (J5) configuration). The control voltage signal is first conditioned by a $7 \mathrm{~Hz}$ low- pass filter $(F)$ then compared to the set point to obtain an analog error voltage. The filter output is also digitized by the DEC.

The system includes several "user loads" which can be switched in or out on demand. They are actuated by the operator via the DEC, however, they are independent of the parasitic control load. Two AC user loads can be connected to the AC bus via solid-state relays. One is connected to a nominal $325 \mathrm{~W}$ resistive load. The second will be connected to a motor load. A user load can also be connected to the DC bus via a DC relay (CR5). This is presently connected to a nominal $325 \mathrm{~W}$ resistive load.

An "emergency" load (3.2kW at $115 \mathrm{~V})$ can also be connected to the AC bus. This load is sufficient to stop the engine. For normal operation, the normally closed emergency load relay (CR10) is held open. In any emergency, the relay is de-energized.

DIGITAL ENGINE CONTROL - The DEC manages engine pressure and electrical load.

The DEC is based on a commercial industrial control computer. The DEC has two processors which share a portion of system memory and other input/output (I/O) resources on a STD-bus. One processor is a dedicated Programmable Logic Controller (PLC). The other is a general purpose PC/AT compatible, DOS processor. The PLC processor is programmed to simulate relay ladder logic. Most routine control functions such as operator input via push-buttons and on-off control of valves and relays are managed by the PLC processor. The PLC also manages all analog and digital input and digital output other than that required for load system control. At present the DOS processor manages an operator display and, most importantly, the load control output. The DOS control software is programmed in " $\mathrm{C}$ ".

Mean Pressure Control - The SPIKE engine is charged with helium from a gas bottle. The helium supply system includes charge and discharge solenoid valves as well as an isolation valve. These are energized by digital outputs from the $\mathrm{DEC}$ computer. In the automatic pressure control mode, the PLC processor controls the helium valves based on the error between measured mean pressure and the desired set-point pressure. When pressure error is outside the proportional band, bang-bang control is used and the appropriate charge or discharge valves are energized. When the error is within the proportional band, the appropriate valves are pulsed on for 0 to $75 \%$ of the measurement and control cycle of $4.2 \mathrm{~s}$. This control approach has been used for the SPRE and found to maintain engine pressure within $\pm 0.2 \%$ whereas more than $\pm 2 \%$ is typical of mechanical regulators.

Load Control - Load control for the SPIKE is accomplished by a voltage controlled shunt resistance, described above. The load control intelligence is primarily contained in the DEC software, though some is also hardwired in the DC control load circuitry. The adjustable set point voltage $\left(V_{\mathrm{g}}\right)$ for the system is determined by the operator. Either AC (rms) or DC bus voltage (V) may be controlled, depending on the position of jumper (J5) at the 
input of the feedback voltage filter ( $\mathrm{F}$ in Fig 3).

The number of (parallel) control loads (N) is determined by linear feedback control algorithm (in software):

$$
N=G_{p}\left(V-V_{s}\right)+G_{i} \int\left(V-V_{s}\right) d t
$$

where $\mathrm{N}$ is the floating point, rather than integer, number of control loads required, $G_{p}$ is the proportional gain constant and $G_{i}$ is the integral gain constant. The integer part of $N$ determines the number of coarse load resistances $\left(R_{c}\right)$ to be switched on. The fractional part of $\mathrm{N}$ is converted to an integer value of between 0 and 255 . This represents the (8 bit) binary load configuration $\left(R_{f}\right)$. The power dissipated by the control load $\left(P_{c}\right)$ is then:

$$
P_{C}=\frac{N}{R} V^{2}=\frac{G_{p}}{R}\left(V^{3}-V^{2} V_{s}\right)
$$

where $R$ is the resistance of one coarse load.

DATA ACQUISITION SYSTEM - Figure 4 is a schematic of the Data Acquisition System (DAS) for the Control and Load Interaction Test Facility. The DAS is based on a (80286/87) PC/AT personal computer.

Measured parameters are first converted to voltages by appropriate analog signal conditioners.

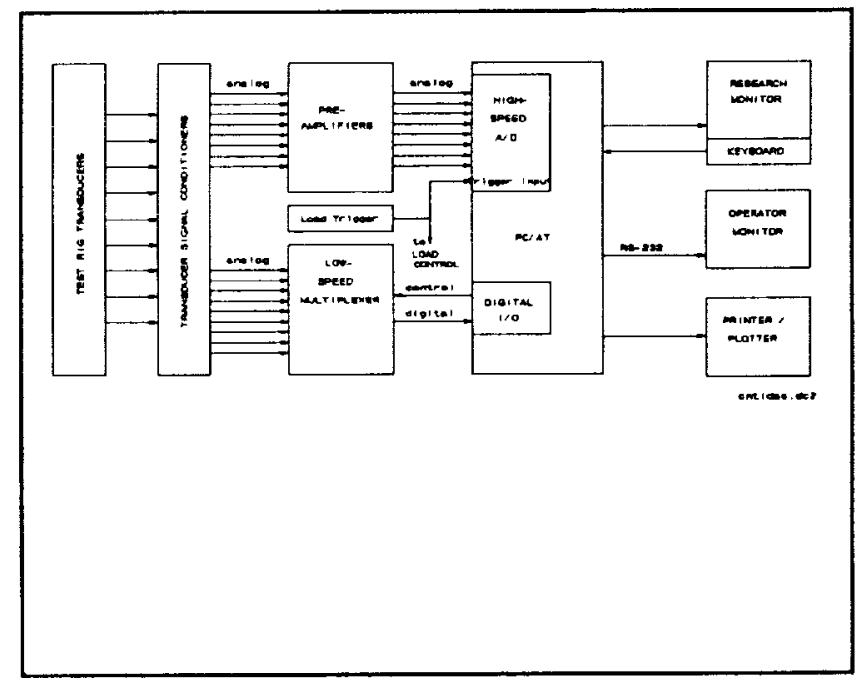

Figure 4 Controls Rig Data Acquisition System Schematic

Quasi steady-state measurements (less than $10 \mathrm{~Hz}$ ) are scanned and digitized by a low speed multiplexer (MUX) which is interfaced to the host PC/AT via a digital I/O board. The PC/AT sends a digital word to the MUX which selects the desired channel and analog-to-digital converter range for the next reading. The analog-to-digital converter is then triggered. When the conversion is complete, the PC/AT reads the digital output and converts it to engineering units for display and storage. Although the MUX is capable of $10 \mathrm{kHz}$ sampling rates $(5 \mathrm{kHz}$ have been achieved with the PC/AT interface), steady-state data is scanned at $1 \mathrm{kHz}$ since accuracy is slightly better and is fast enough for this data.

Acquisition of periodic $(50-100 \mathrm{~Hz})$ and transient dynamic measurements are the primary objectives of the DAS. These measurements are first preamplified by matched differential amplifiers, then scanned and digitized by a 12bit high-speed analog/digital (A/D) converter installed in the PC/AT. The 16 channel A/D is relatively unique in that it can be programmed to sequentially sample up to 4 groups of 4 simultaneous channels at a time, at up to $50 \mathrm{kHz}$ per channel. The A/D has $256 \mathrm{k}$ words of on board memory so that high-speed data acquisition can proceed independent of the host PC/AT. The A/D can be programmable for either software or external triggering.

For routine monitoring and recording of steady-periodic data the A/D is first programmed to sample one data channel (usually piston position) at a known sampling rate. This data is analyzed to determine the operating frequency (f). Then all dynamic channels are sampled at $\left(f_{3}\right)$ a multiple of the operating frequency determined by:

$$
f_{s}=\frac{N_{s}}{N_{c}} f
$$

where $N_{0}$ is the number of samples recorded (typically 257) and $N_{c}$ is the number of engine cycles (typically 4 ) over which the data is to be recorded. This sampling strategy minimizes error in calculated amplitude and phase. The data for each channel is Discrete Fourier Transformed (DFT) to obtain the $1^{\text {st }}$ harmonic amplitude and phase. Since the raw data is obtained for an arbitrary time window the phase of each data channel is shifted relative to a reference channel (typically piston position). The phase is corrected to account for time skew between non-simultaneous data channels. In addition, the mean, RMS and total harmonic distortion for each channel are calculated. These calculated values are then converted to engineering units, stored along with steady-state data and displayed. The raw dynamic data, in integer form, is stored separate from the steady-state measured data for permanent record readings. While very accurate amplitude measurement of dynamic signals is routine and largely dependent on calibration of the transducers, signal conditioners, etc.; obtaining very accurate phase measurements has been more difficult. Accuracy of phase measurements depends on the A/D converter, effective resolution of the digitized data and processing algorithm, in addition to the frequency response of transducers, signal conditioners and amplifiers. Tests of this dynamic DAS have shown that phase measurements with less than $\pm 0.1^{\circ}$ uncertainty can be made for signal amplitudes greater than $10 \%$ of the full scale range of the A/D converter, and for signal amplitudes near $(>80 \%)$ full scale, measurements within $\pm 0.02^{\circ}$ have been achieved. These errors include the effect of pre-amplifiers included on all dynamic channels. The error between channels, in the same simultaneous group, is slightly better than for intra- 
group channels. In either case satisfactory phase accuracy $\left( \pm 0.1^{\circ}\right)$ is routinely obtained with this system.

For acquisition of transient data the $A / D$ is programmed to sample data at the highest possible frequency consistent with the duration of the anticipated event and available onboard memory. The A/D continuously records pre-trigger data to its on-board memory, over-writing the oldest data, while waiting for the trigger event to occur. Once the trigger is detected, post-trigger data is recorded to memory for a specified number of readings. Following completion of the event, the data is permanently saved, and the DAS resumes monitoring steady-state and periodic data. On-line plots of the transient data can be displayed for preliminary data evaluation. However, most analysis of transient data is performed off-line after the test is completed.

\section{TEST RESULTS}

Tests of the SPIKE engine were conducted to characterize the steady-state performance of the engine/ alternator and control system. The engine/alternator's characteristic power vs load voltage was determined by maintaining all engine parameters fixed while the control set point voltage was changed. Several parameter changes were also made to the load control. The effect of these changes on the system was evaluated by running the engine at different heater temperatures. Figure 5 plots the total electric power dissipated in the parasitic and user loads vs load voltage amplitude for both engine/alternator and control characterization test.

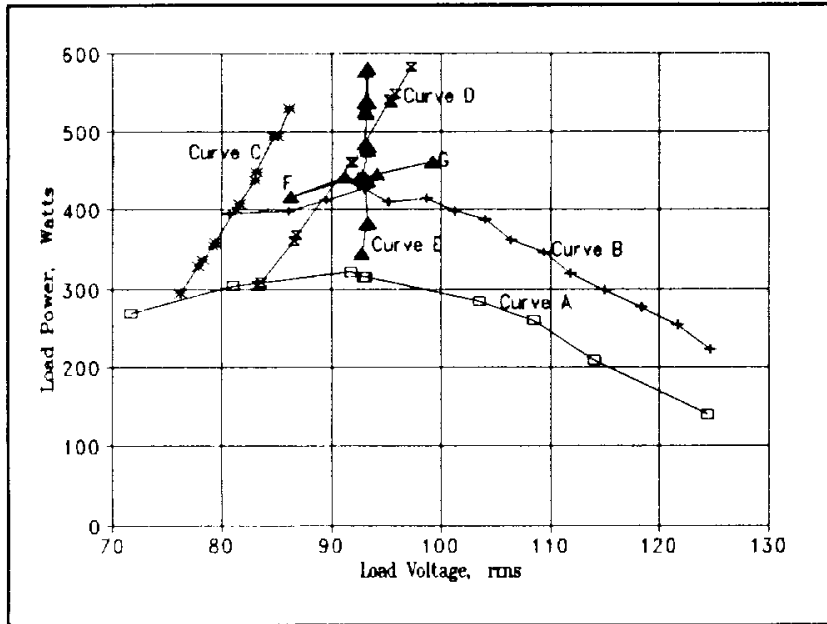

Figure 5 Load Power versus Load Voltage

ENGINE/ALTERNATOR - The characteristic engine/ alternator power curves ( $A$ and $B$ in Fig 5) show the effect of load voltage on total electric power output, for constant heater temperatures of 500 and $575^{\circ} \mathrm{C}$. Although the FPSE/LA is operating at less than its rated heater temperature, pressure and voltage, the observed results are unexpected, in that the power decreases as the voltage increases. Ideal FPSE/LAs (which behave as a linear system with constant coefficients) have a power curve that increases with voltage square. Practical FPSE/LAs [6] have power curves which increase with load voltage but less strongly than an ideal system. The observed power drop off is due to losses in the alternator and non-linear behavior in the engine. Fig 6 shows the piston and displacer amplitude

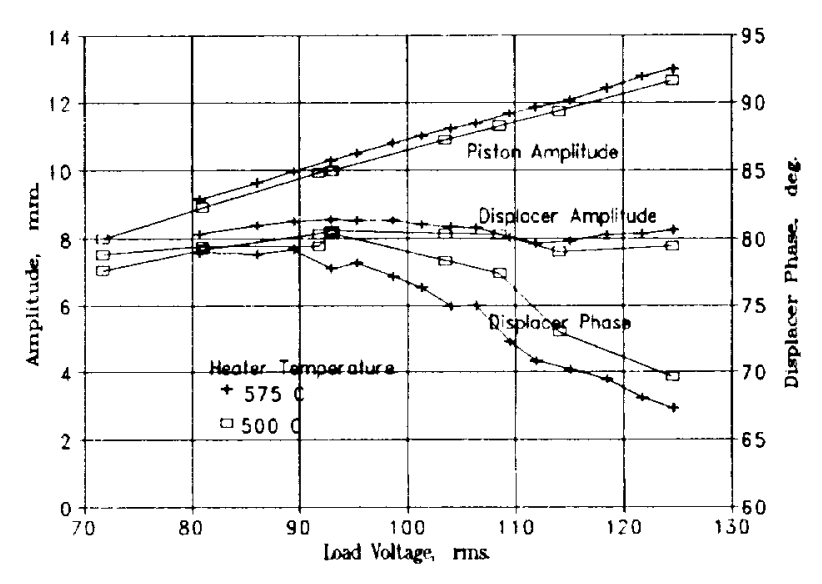

Figure 6 Piston and Displacer Dynamics vs Load Voltage.

and displacer phase vs load voltage. The piston amplitude is proportional to load voltage indicating linear behavior of the alternator and the bounce space gas spring. However, when extrapolated to zero load voltage the piston amplitude is slightly above zero suggesting that there is some nonlinear behavior. The major non-linear response is in the displacer amplitude and phase. The displacer amplitude is almost constant where a linear model would suggest a linear function of piston amplitude. Also, the displacer phase drops substantially where a linear model suggests it should be constant. A drop in heater, and thereby expansion space temperatures, may in part explain the displacer's behavior. However, measured inside heater temperatures are nearly constant $\left( \pm 5^{\circ} \mathrm{C}\right)$ for each controlled constant outside heater temperature. A simpler, and more likely, explanation is that the displacer is rubbing thereby limiting its amplitude to about 7 to $8 \mathrm{~mm}$. This latter hypothesis is further supported by the fact that the engine stalls as heater temperature is increased above $650^{\circ} \mathrm{C}$.

LOAD CONTROL - Curves $C$ and D in Fig 5 show the load control characteristic for two levels of proportional feed-back gain with no integral feed-back. The slopes of the two curves are characteristic of the control algorithm. The proportional gain for curve $\mathrm{C}$ was $50 \%$ higher than curve D. The set point voltage for both were the same. As expected there is a slight curvature in the power vs voltage characteristics and curve $C$ is steeper than $D$. Curve $E$ shows the influence of adding integral feed-back to the control algorithm. The steady-state behavior is dominated by the integral control resulting in good voltage regulation. The difference in slope between the load control and FPSE/LA characteristics is an indication of the system stability. The greater this difference is, up to a $90^{\circ}$ intersection, the more stable the system should be. In fact, 
the case with integral feed-back was the most stable in that the system was less jittery.

TRANSIENT RESPONSE - Curve E of Fig 5 includes data for which the AC user load was first switched in (point F) then out (point $G$ ). In both cases the system returned to the set point within $2-4 \mathrm{~s}$. These transients are plotted against time in Fig 7. Each point is the amplitude, averaged over 4 cycles $(\approx 0.07 \mathrm{~s})$, recorded at $\approx 2 \mathrm{~s}$ intervals. These curves do not have sufficient time resolution to show the transient system dynamics. However, they do suggest the control is reasonably effective.

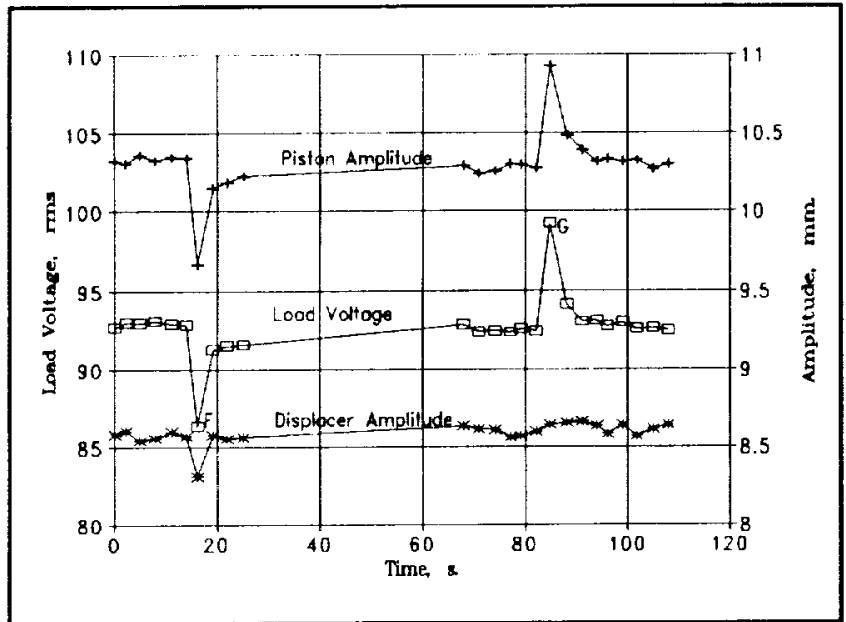

Figure 7 Transient Response to User Load Change.

\section{CONCLUSIONS}

This paper describes a test facility designed for evaluating control and load interaction characteristics of power systems based on FPSE/LA power converters. The results to date have confirmed the general behavior of the engine and control. Minor hardware problems were identified which effect the dynamic behavior of the engine and must be corrected. Data from this facility will be useful for experimental verification of dynamic analyses and improving understanding of performance characteristics of FPSE/LA base space power systems. Better understanding of single engine FPSE/LA system dynamics is expected to lead to multi-engine system in the future.

\section{REFERENCES}

[1] Winter, J.M., "The NASA CSTI High Capacity Power Program", NASA TM-105240, AIAA-91-3629, Conf. on Advanced Space Exploration Initiative Technologies, Clev., OH, Sept. 1991.

[2] Kankam, M., and Rauch, J.S., "Comparative Study of Dynamic Analyses of Free-Piston Stirling Engines," $26^{\text {th }}$ IECEC, Vol. 5, American Nuclear Society, LaGrange Park, IL, 1991, pp 314-319. (Also NASA TM-104491).

[3] Redlich, R.N., Berchowitz, D.M., "Linear Dynamics of
Free-Piston Striling Engines," Proc. Instr. Mech. Engrs., Vol 199, \#A3, pp 203-213, 1985.

[4] Berchowitz, D.M., "The Development of a $1 \mathrm{~kW}$ Electric Output Free Piston Stirling Engine Alternator Unit", Proc 18th IECEC, Orlando, Florida, Aug 1983, paper 839146, pp 897-901.

[5] Berchowitz, D.M., "Stirling Cycle Engine Design and Optimization", PhD Thesis Univ. of Witwatersrand, Johannesburg, So. Africa, Aug. 1986.

[6] Brown, A.T., "Space Power Demonstrator Engine, Phase I Final Report", NASA CR-17955, May 1987.

[7] Slaby, J., "1988 Overview of Free-Piston Stirling Technology for Space Power at the NASA-LeRC", NASA TM-100798, NASA-LeRC, Cleveland, Ohio, 1988.

[8] Cairelli, J.E., et al, "Update on Results of SPRE Testing at NASA Lewis", Proc 26th IECEC, vol 5, pp 217222, Boston, MA, Aug. 1991.

[9] Dochat, G., Dhar, M., "Free-Piston Stirling Component Test Power Converter", Proc 26th IECEC, vol 5, pp 239244, Boston, MA, Aug. 1991.

[10] Shaltens, R.K., Schreiber, J.G., "Status of the Advanced Stirling Conversion System Project for $25 \mathrm{~kW}$ Dish Stirling Applications", Proc 26th IECEC, vol 5, pp 388394, Boston, MA, Aug. 1991.

[11] Niedra, J.M., "Analog Synthesized Fast-Variable Linear Load," Proc 26th IECEC Boston, MA, Aug. 1991, (Also NASA CR-187155). 


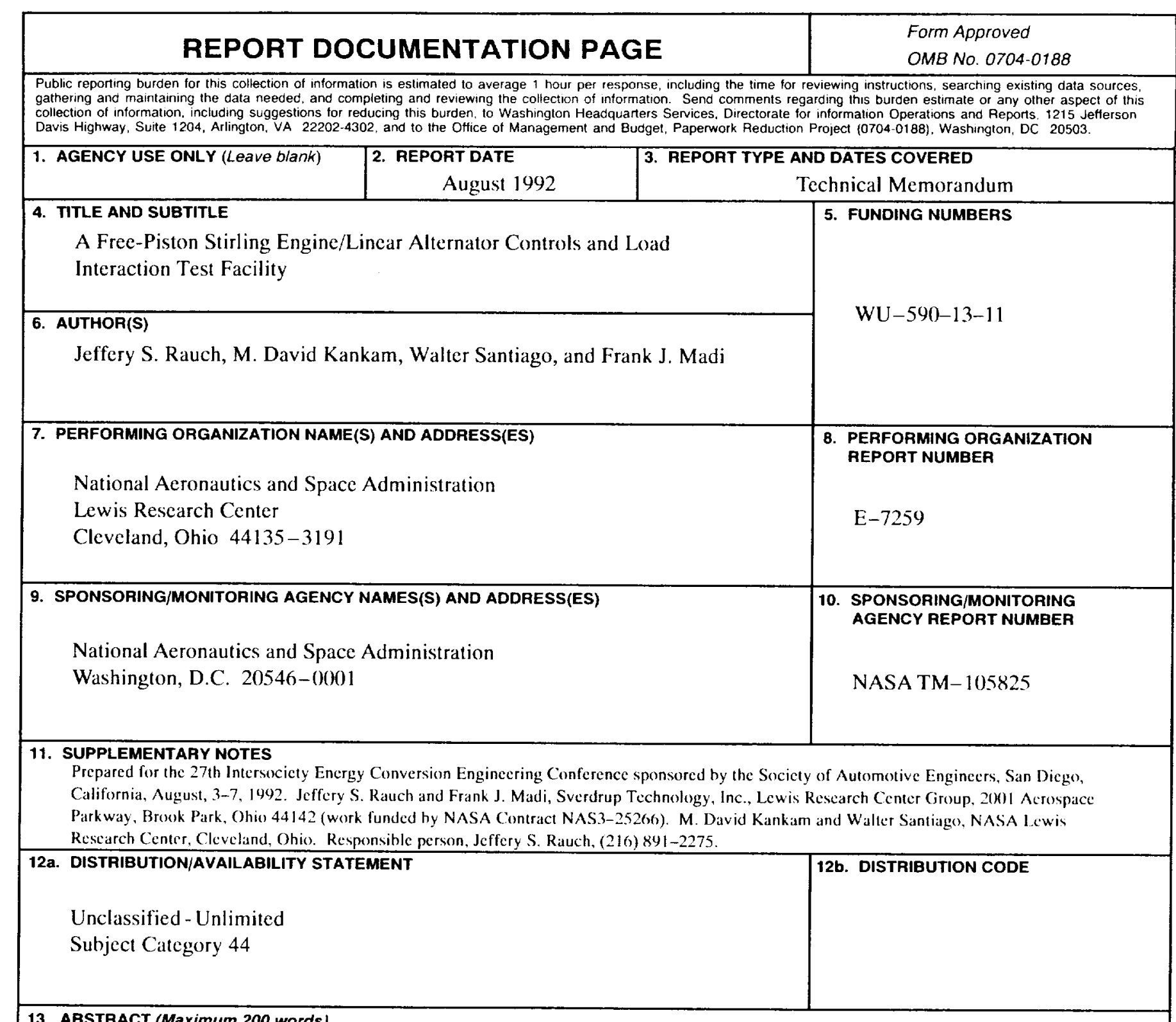

\section{ABSTRACT (Maximum 200 words)}

A test facility at NASA Lewis has been assembled for evaluating: free-piston Stirling engine/linear alternator control options, and interaction with various electrical loads. This facility is based on a "SPIKE" engine/alternator. The paper describes the engine/alternator, a multi-purpose load system, a digital computer based load and facility control, and a data acquisition system with both steady-periodic and transient capability. Preliminary steady-periodic results are included for several operating modes of a digital AC parasitic load control. Preliminary results on the transient response to switching a resistive $\mathrm{AC}$ user load are discussed.

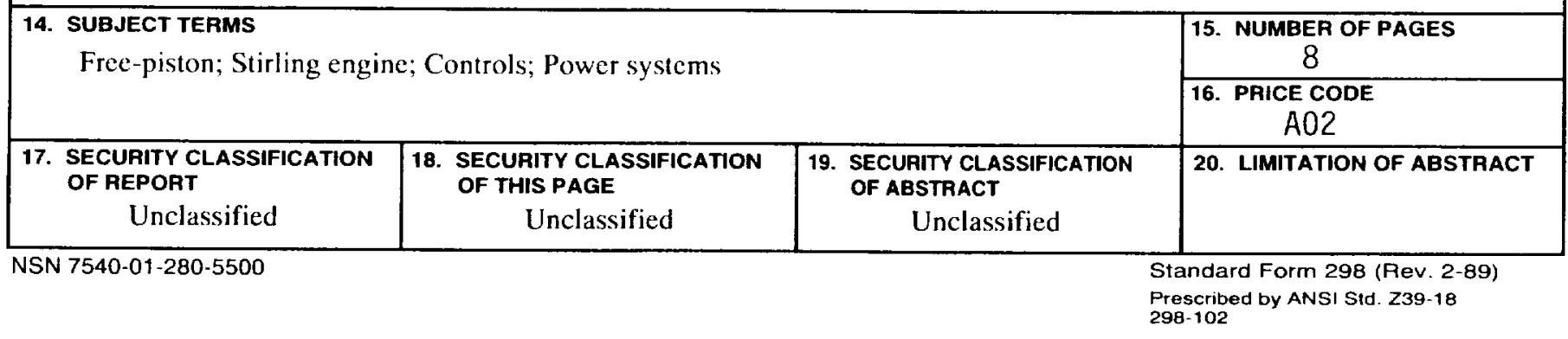


